Andrzej Wieniewski*, Bożena Skorupska*, Edward Szczerba*, Michat Woch ${ }^{*}$,Adam Mańka*

\title{
UPDATING OF CLASSIFICATIONS IN NON-FERROUS METAL ORE PROCESSING PLANTS**
}

\section{Introduction}

The classification process in ore enrichment plants is primarily carried out in hydrocyclones. The hydrocyclone type and size is selected depending on the characteristics of the classified feed and the technological requirements associated with the particular operation. Until recently, only hydrocyclones manufactured by ZAM Kety were used in Polish non-ferrous metal ore enrichment plants. These hydrocyclones were designed in the 1960s at the Institute of Non-Ferrous Metals. Depending on the technological requirements of a specific classification circuit, these hydrocyclones differed only in the size and taper of their conical sections. Due to the high throughputs of ore enrichment plants, many hydrocyclones are used - For example: a single process line in Rudna Concentrator (even side) has more than 150 working hydrocyclones.

Hydrocyclones manufactured by ZAM Kety offer considerable potential with regards to gaining working parameters, and in particular:

- a wide range of cut sizes $\left(d_{50}\right)$ : from 0.02 to $0.2 \mathrm{~mm}$,

- a wide potential as regards the thickening of supplied feed: from 50 to more than $700 \mathrm{~g} / \mathrm{l}$,

— high unit capacities values: from 20 to more than $600 \mathrm{~m}^{3} / \mathrm{h}$.

Available classification efficiency values $(E)$ differ for individual classification circuits - however in general they do not exceed $80-85 \%$. In order to ensure the proper classification

* Institute of Non-Ferrous Metals, Gliwice

** The report contains the results obtained during the implementation of Project POIG.01.03.01-24-019/08-00: „New technologies and new designs of machines and equipment for the enrichment and metallurgical processing of raw materials". 
process efficacy and capacity, all hydrocyclones are currently manufactured with replaceable apexes and vortex finders. This selection of apexes and vortex finder diameters, as well as the type of linings fitted affect both classification quality and service life of elements, which in turn determines operating costs. Elements that suffer the most wear: the hydrocyclone interior and above all, the apexes, are covered with replaceable linings. In general, these are rubber linings. Considerable progress has been achieved by introducing apexes and vortex finders made from polyurethane and silicon carbide. In particular, the latter are characterised by their exceptionally high abrasion resistance. Currently, classification circuits in Polish ore enrichment plants are undergoing modernisation. This doesn't have a replacement character, but concentrates more on introducing new systems and solutions, intended to improve classification efficacy, with the simultaneous unification of current working hydrocyclones. The number of classification circuits will be considerably reduced as a result of replacing the smaller diameter $(350 \mathrm{~mm})$ hydrocyclones with $500 \mathrm{~mm}$ diameter units.

New hydrocyclone solutions offered by Krebs Engineering and Weir Minerals are characterised by a modified design compared to those formerly used. Primarily, these solutions involve the structural modifications of feed inlet. In 2008, IMN began to develop a new hydrocyclone for classifying fine-grained suspensions [5]. Design and operation knowledge, acquired through experience gained at the enrichment plants, was brought to bear in order to develop the new hydrocyclone. As a result of this, a new hydrocyclone construction was developed - the $\varnothing 500 / 12^{\circ}$ type with modified geometrical proportions. Classification parameters have improved due to this modification, and providing the hydrocyclone with automatic control system ensuring constant pressure values of delivered feed, it is now possible to maintain stable classification conditions at all times. Tests have proved that the new hydrocyclone is capable of replacing previous $\varnothing 350$ and $\varnothing 500$ units, which would allow a reduction in the number of operating hydrocyclones and in turn simplify spare part management $[5,6]$.

\section{Currently applied hydrocyclone solutions}

New solutions are offered by two leading companies:

- Krebs Engineering - manufacturer of modern gMAX® hydrocyclones and other equipment,

— Weir Minerals — manufacturer of Cavex ${ }^{\circledR}$ hydrocyclones.

The gMAX ${ }^{\circledR}$ hydrocyclone is a new construction which has been developed in order to improve classification sharpness, while maintaining a high capacity. This new hydrocyclone type has a modified inlet head with a two part conical section, characterised by different integrated angles. The redesigned inlet head also has a lengthened vortex finder, which reduces feed turbulences inside the chamber and as a consequence, limits the penetration of coarser material into the hydrocyclone overflow. The new design also allows for the possibility 
of maximising the tangential velocity of classified particles in the upper part of the hydrocyclone, improving the separation of fine particles [3]. Cavex $®$ is a unique inlet head solution. As with the Krebs design, the feed inlet has an involute type shape, allowing a laminar entering of suspension into the hydrocyclone, thus improving the classification process. Moreover, Weir Minerals emphasises the significance of the fact that there are no sharp edges in the hydrocyclone, which contributes to an improvement in hydrocyclone operation and reduced lining wear. Both Krebs and Weir Minerals offer hydrocyclones with various diameters — ranging from 100 to $800 \mathrm{~mm}$, with adequate inlets, apexes and vortex finders. Clusters from both manufacturers can operate in a fully automated system.

A cluster of Cavex $\varnothing 400$ hydrocyclones from Weir Minerals currently operates, in the classification circuit of spiral classifiers overflow, at ZGH Boleslaw. The leading hydrocyclone manufacturer in Poland is the Industrial Equipment Production Plant ZAM Kety. The plant offers a hydrocyclone series of types with diameters ranging from 100 up to $750 \mathrm{~mm}$. The new hydrocyclone designed at the IMN, type $\varnothing 500$, adds to ZAM Kety offer.

The design of the implemented modified hydrocyclone is characterised by:

- reduced included angle of the hydrocyclone conical section,

- lengthened cylindrical part.

These technological changes positively effect hydrocyclone operation in two ways:

- improvement in separation efficacy [6],

— improvement of machine output.

\section{Preliminary tests based on numerical modelling methods}

In recent years, numerical methods (CFD) have been employed for studying stream flow in hydrocyclone [1, 2]. Moreover, the Institute researchers initiated these numerical modelling-based studies while carrying out design work on the new hydrocyclone. It has been assumed that a turbulent flow occurs in a hydrocyclone, and from this, a Standard turbulence model $k_{\varepsilon}$ has also been assumed. This flow is characterised by the following equations:

- continuity:

$$
\frac{\partial \rho}{\partial t}+\nabla \cdot(\rho+\mathbf{w})=0
$$

- conservation of momentum equation:

$$
\frac{D(\rho \cdot \mathbf{w})}{D t}=\mu \cdot \nabla^{2} \cdot \mathbf{w}-\bar{\nabla} p
$$


— turbulent kinetic energy transport $k$ and dissipation rate $\varepsilon$ :

$$
\kappa=\frac{1}{2}\left(\left\langle u_{1}^{\prime 2}\right\rangle+\left\langle u_{2}^{\prime 2}\right\rangle+\left\langle u_{3}^{\prime 2}\right\rangle\right)
$$

where:

$$
\begin{aligned}
& \rho \text { - fluid density, } \\
& \mathbf{w} \text { - velocity vector, } \\
& \mu \text { - fluid viscosity, } \\
& v \text { - velocity vector components. }
\end{aligned}
$$

The area of computations covers the hydrocyclone interior.

Figure 1 shows the discretisation of selected surfaces in this area, consisting of approximately 113000 elements. „Inlet” type boundary condition has been taken at the inlet. A constant feed flow of $250 \mathrm{~m}^{3} / \mathrm{h}$ has been preset. An „Outflow” type boundary condition has been assumed at the hydrocyclone underflow and overflow.

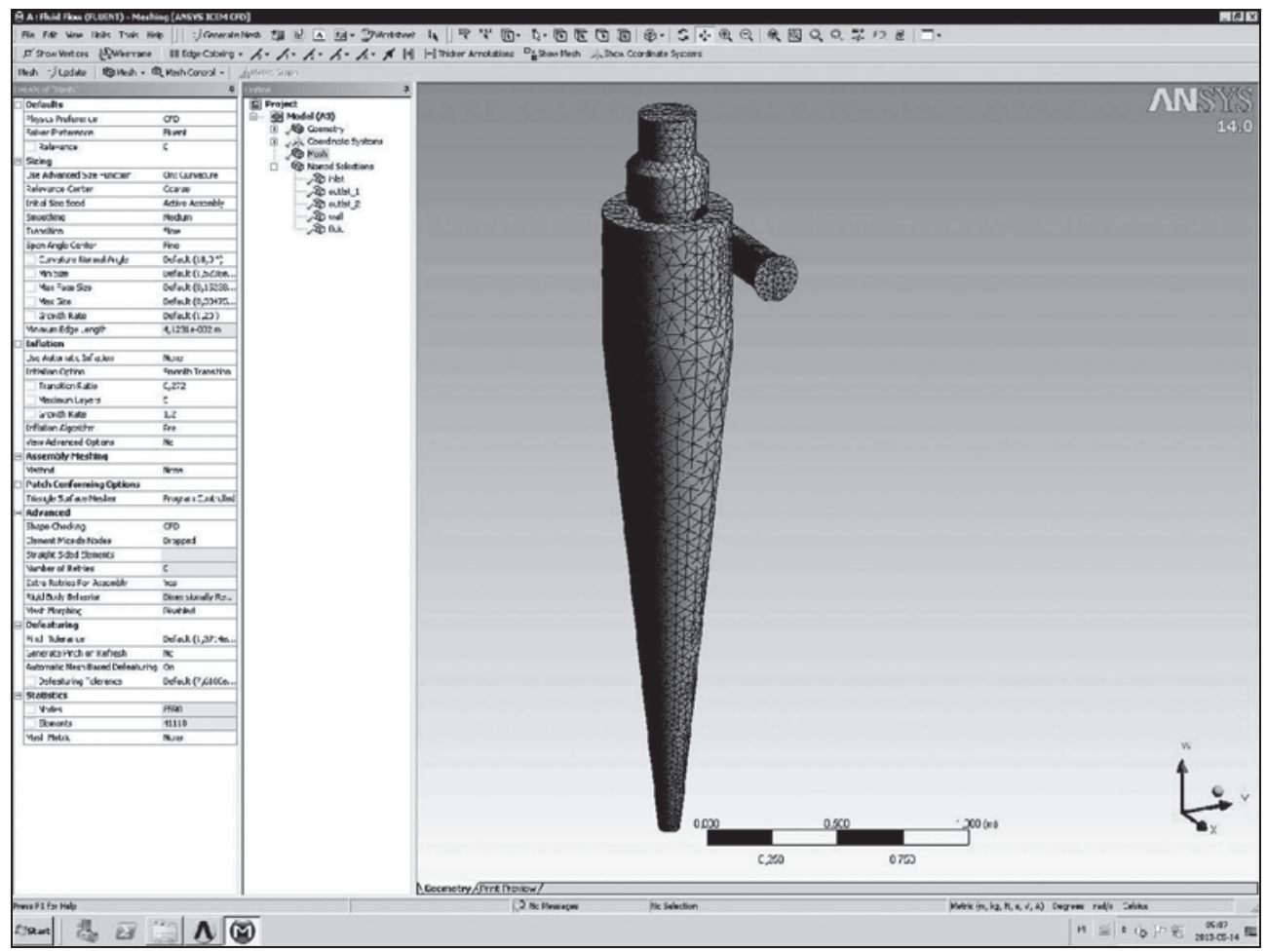

Fig. 1. Preparation of mesh for numerical modelling 
Figure 2 presents simulation results for the stream velocity in the HC500/12 hydrocyclone, derived from modelling. Studies based on modelling are being used, not only to verify, but also optimise the new hydrocyclone design.

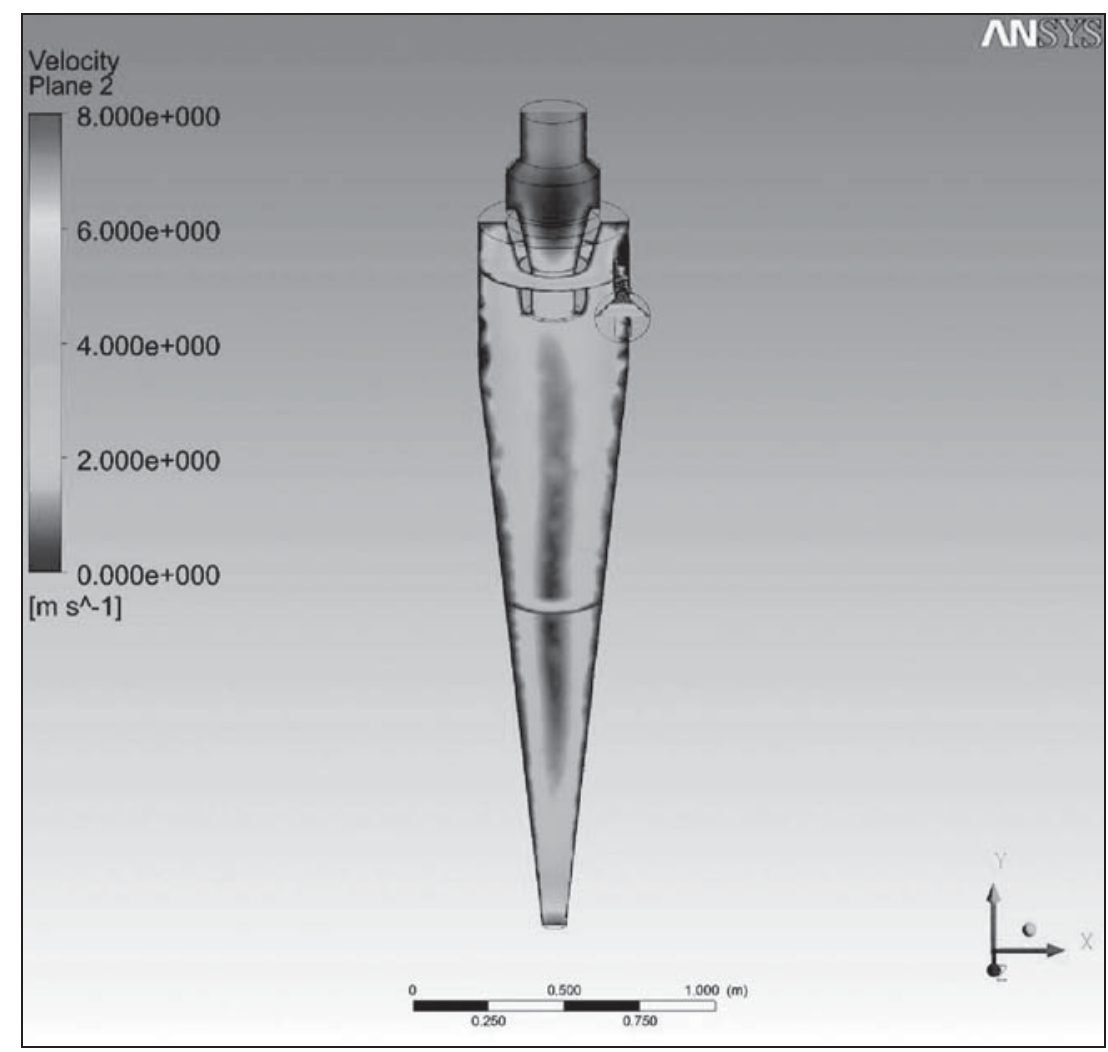

Fig. 2. Simulation results for stream velocity distribution in a hydrocyclone

\section{Technological tests of classification in $\mathrm{HC500/12}{ }^{\circ}$ hydrocyclones in copper ore enrichment process}

\subsection{Classification circuit characteristics}

At the Lubin Concentrator industrial station, in place of cluster no. 141 in line I, a new cluster consisting of $4 \mathrm{HC} 500 / 12^{\circ}$ type hydrocyclones was built-in. The new cluster can be supplied with feed from the overflows of spiral classifiers, or from the regrinding cylpebs mill no. 151. The cluster's automatic control system provides constant control as well as the accurate classification of circuit operation based on feed pressure and density measurements. In order to improve operating parameters of the new $\varnothing 500 / 12^{\circ}$ hydrocyclone, its metal body 
was covered with new linings based on silicon carbide composites. These linings have excellent anti-abrasive properties. In the case of tests with apexes, which were performed at Boleslaw Concentrator, it was observed that the service life of these apexes increases by 4-5 times when compared with polyurethane apexes.

\subsection{Automation system characteristics}

Clusters of $\mathrm{HC} 500 / 12^{\circ}$ hydrocyclones are provided with a control system to ensure the stabilisation of the main parameters of cluster operation including: feed pressure, density and level in the feed sump. The central element in the system is a control cabinet equipped with a PLC controller. The system is operated via a control panel installed on the cabinet. The main screen displays a cluster of four hydrocyclones with a system supplying feed to the cluster.

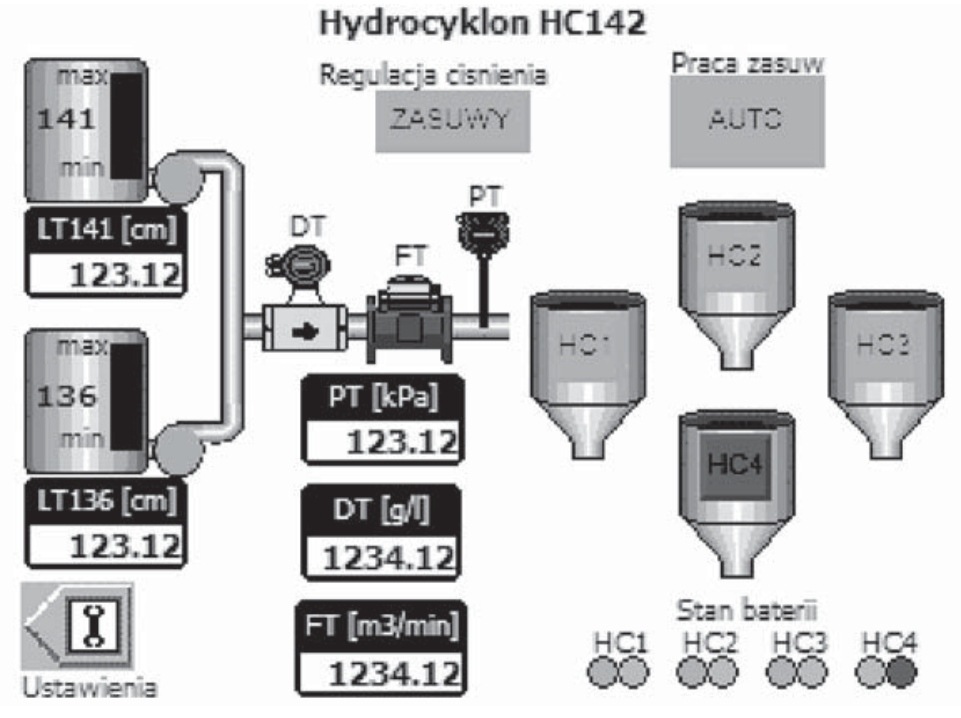

Fig. 3. Main screen

Among other things, the system is equipped with an isotope densimeter, feed flowmeter and pressure gauge. The readings from these instruments are displayed on the main screen.

\section{Feed pressure control system}

The gate valve-based pressure control system maintains feed pressure within a desired range. Each hydrocyclone is equipped with a gate valve capable of cutting off feed supply. Gate valve control can be executed manually or automatically. Operation mode is selected with the Gate valve operation push-button, which sets the operation mode: 
- MANUAL - manual operation mode that allows the closing and opening of individual hydrocyclones using $\mathrm{HC} 1, \mathrm{HC} 2, \mathrm{HC} 3, \mathrm{HC} 4$ push-buttons on the hydrocyclone icons.

- AUTO - automatic operation mode controls the gate valves depending on the pressure of feed supplied to the cluster. The control system checks the pressure, and, opens or closes knife gate valves accordingly. The control system will not react as long as feed pressure remains within the assumed range. When the pressure value increases above a predetermined upper limit of the assumed zone, the system opens gate valves. If high pressure still remains after the determined (preset) time period, the system opens another gate valve. If the pressure drops below the lower interval limit, the system closes gate valves one by one

In AUTO operation mode it is not possible to take control of the system via pushbuttons on hydrocyclone icons. In this case, they indicate the state of the control signal (relay in control cabinet). This signal should coincide with signals of limit gate valve positions visible on the panel and defined as 'Cluster state'.

\section{Density control in sump 141}

The density adjuster is intended to operate a butterfly valve in the line supplying water to sump 141 so as to maintain the preset feed density $(S P)$.

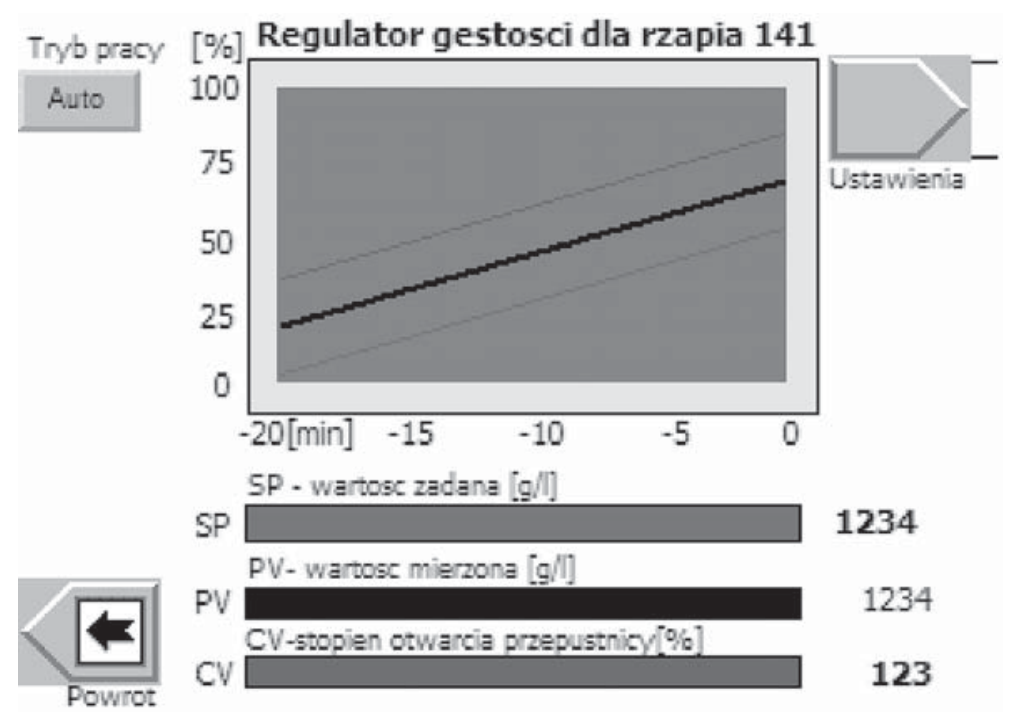

Fig. 4. Screen of density adjuster in sump 141

The adjuster screen displays charts with the following basic control-related parameters: measured density, preset density and water butterfly valve opening degree. The operation 
mode key adjusts the mode of operation. In Manual mode it is possible to adjust the butterfly valve opening degree manually by changing the adjuster output value from $0-100 \%$.

\subsection{Classification results at the Lubin Concentrator}

The tested cluster was feed supplied from either the overflows of spiral classifiers or from the regrinding cylpebs mill 151. Table 1 specifies the operating conditions of the classification system during tests, in which feed was supplied via the classifier overflow.

TABLE 1

Comparison of operating conditions for $\mathrm{HC} \mathrm{500/12^{ \circ }}$ hydrocyclones at Lubin Concentrator (feed was derived from overflows of spiral classifiers)

\begin{tabular}{|c|c|c|c|c|c|c|c|c|}
\hline \multirow{2}{*}{$\begin{array}{l}\text { Hydrocyclone } \\
\text { in battery }\end{array}$} & \multirow{2}{*}{$\begin{array}{l}\text { Number } \\
\text { of test }\end{array}$} & \multicolumn{2}{|c|}{$\begin{array}{l}\text { Amount of feed, } \\
\qquad\left[\mathrm{m}^{3} / \mathbf{h}\right]\end{array}$} & \multirow{2}{*}{$\begin{array}{l}\text { Pressure, } \\
\text { [bar] }\end{array}$} & \multirow{2}{*}{$\begin{array}{c}\text { Densimeter } \\
\text { on feed, } \\
{\left[\mathrm{g} / \mathrm{dcm}^{3}\right]}\end{array}$} & \multicolumn{3}{|c|}{$\begin{array}{c}\text { Concentration (weighted), } \\
\qquad\left[\mathrm{g} / \mathrm{dcm}^{3}\right]\end{array}$} \\
\hline & & $\begin{array}{l}\text { for } \\
\text { cluster }\end{array}$ & $\begin{array}{l}\text { for } \\
1 \mathrm{HC}\end{array}$ & & & feed & underflow & overflow \\
\hline \multirow{4}{*}{ H 1} & 1 & 576 & 191 & 0,75 & 1180 & 1176 & 1667 & 1076 \\
\hline & 2 & 617 & 206 & 0,88 & 1164 & 1171 & 1688 & 1074 \\
\hline & 3 & 654 & 164 & 0,57 & 1160 & 1162 & 1628 & 1067 \\
\hline & 4 & 718 & 239 & 1,12 & 1180 & 1188 & 1790 & 1072 \\
\hline \multirow{4}{*}{ H 2} & 1 & 576 & 191 & 0,75 & 1180 & 1176 & 1715 & 1086 \\
\hline & 2 & 617 & 206 & 0,88 & 1164 & 1171 & 1720 & 1077 \\
\hline & 3 & 654 & 164 & 0,57 & 1160 & 1162 & 1639 & 1074 \\
\hline & 4 & 718 & 239 & 1,12 & 1180 & 1188 & 1798 & 1082 \\
\hline \multirow{4}{*}{ H 3} & 1 & 576 & 191 & 0,75 & 1180 & 1176 & 1665 & 1082 \\
\hline & 2 & 617 & 206 & 0,88 & 1164 & 1171 & 1677 & 1074 \\
\hline & 3 & 654 & 164 & 0,57 & 1160 & 1162 & 1623 & 1073 \\
\hline & 4 & 718 & 239 & 1,12 & 1180 & 1188 & 1790 & 1072 \\
\hline
\end{tabular}

The tests were carried out for a cluster of hydrocyclones equipped with apex and vortex finders of different sizes. The table presents capacity levels and concentration values obtained for feed and classification products. The tests demonstrated very good cluster operation, which is indicated by high classification efficiency index results, calculated using the following formula:

$$
E_{c}=\frac{P \cdot Z d+W \cdot Z g}{100}
$$




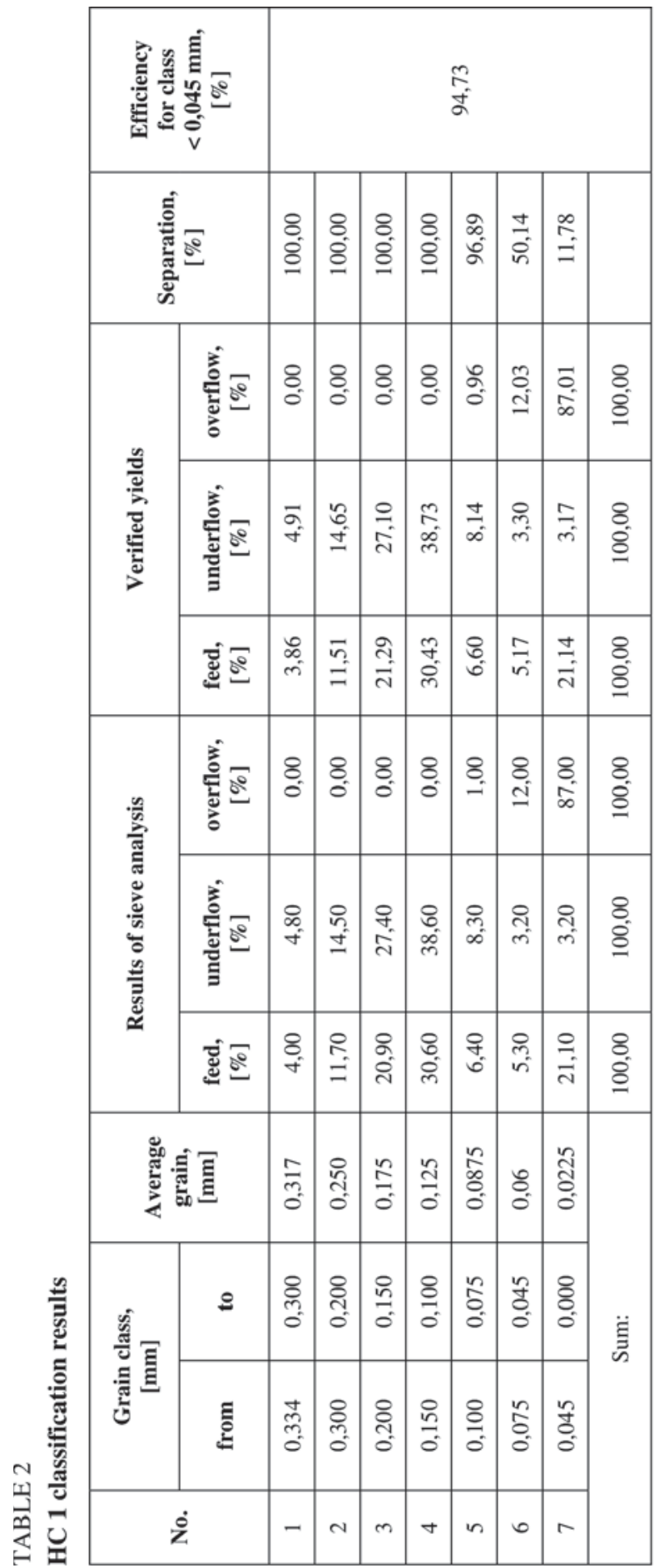

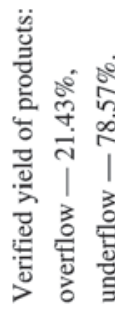




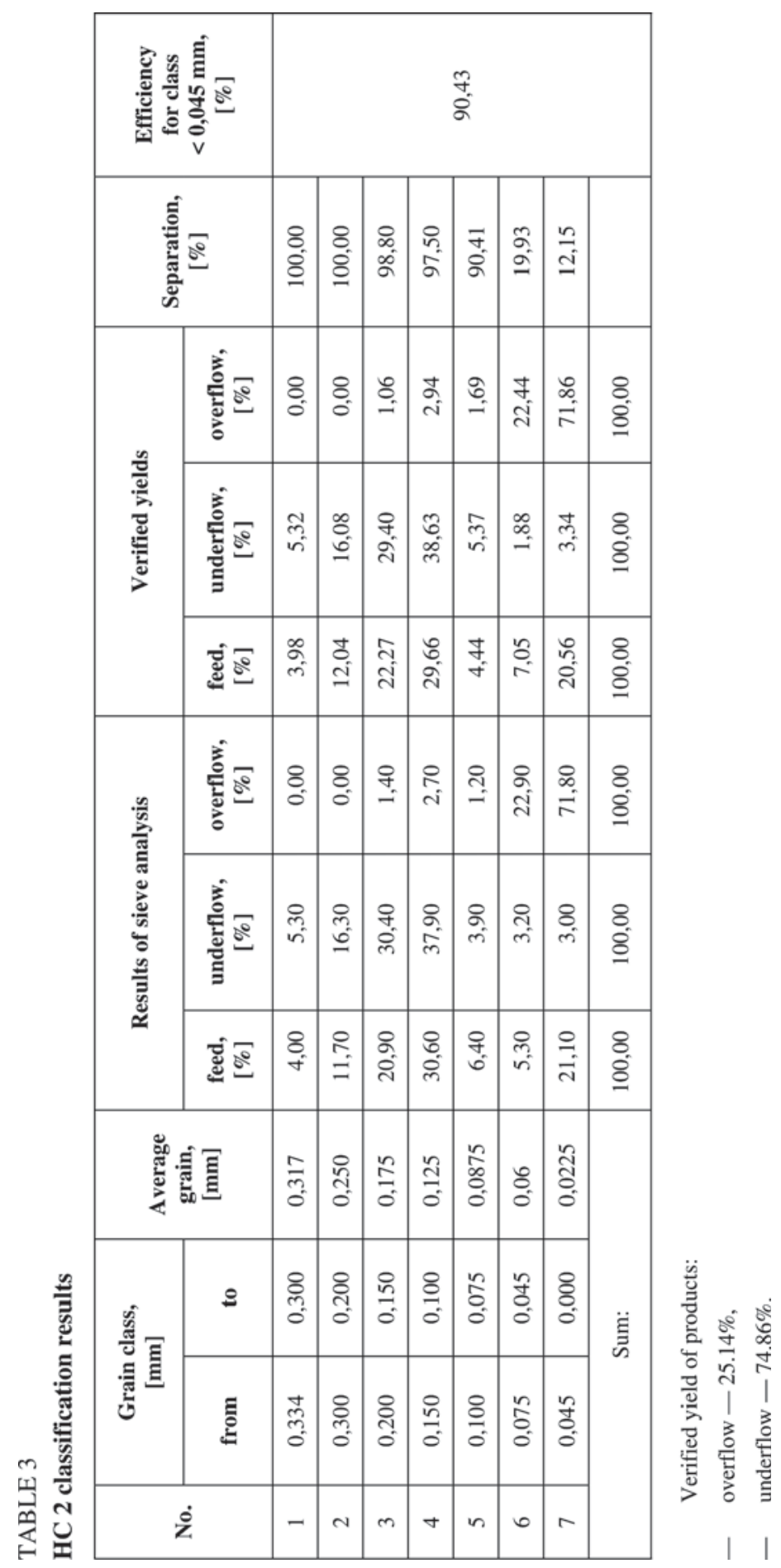




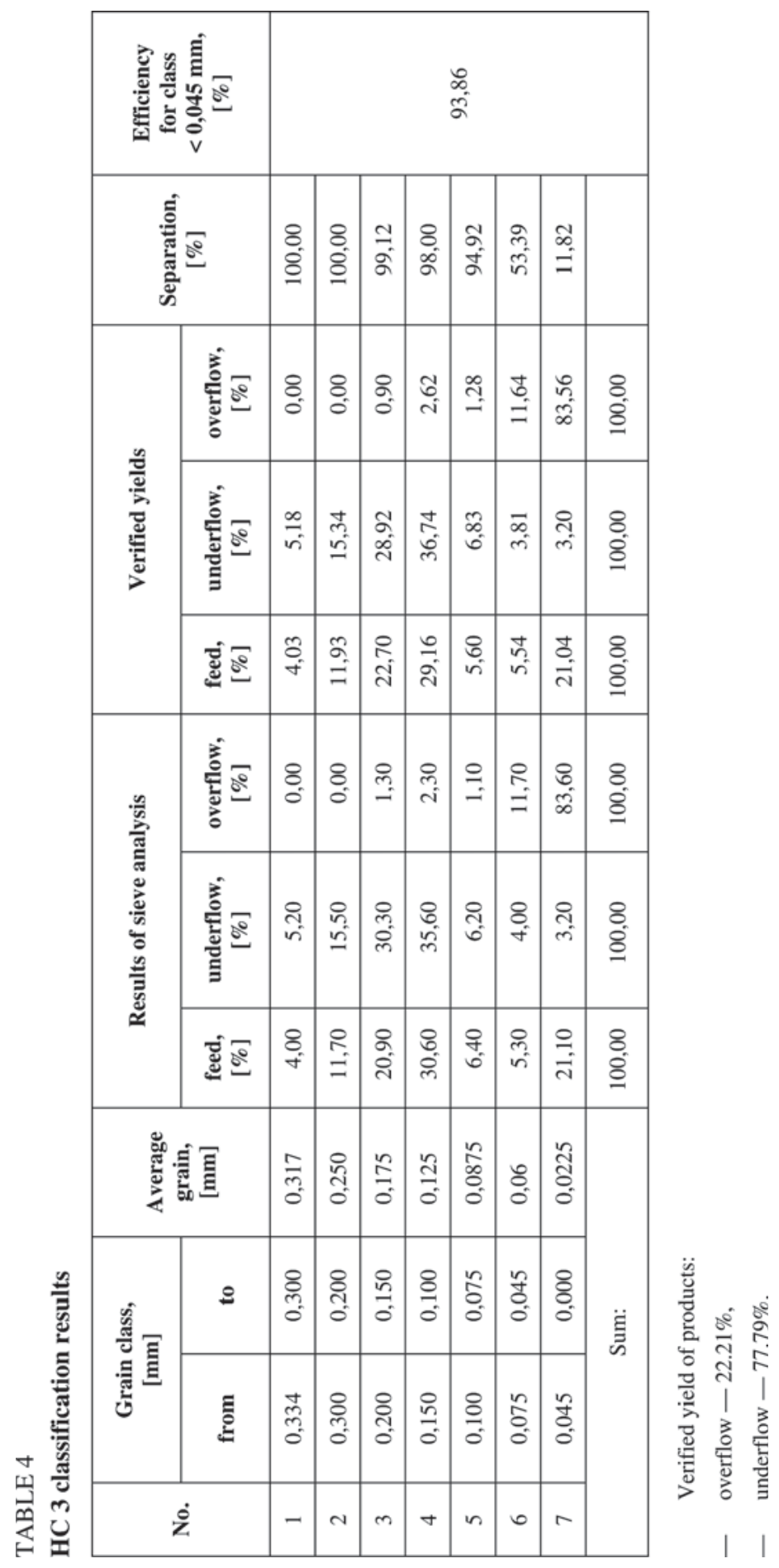


where:

$P$ - yield of hydrocyclone overflow,

$\mathrm{Zd}$ - fine grain content in overflow,

$W$ - yield of hydrocyclone underflow,

$\mathrm{Zg}$ - coarse grain content in underflow.

Efficiency has been calculated for grain size $d_{80}$ in overflow, ranging from 42 to $55 \mu \mathrm{m}$. The $45 \mu \mathrm{m}$ size was taken for calculation purposes.

A high efficiency classification (reaching 90-95\%) was achieved, and the hydrocyclone overflows sent for a rougher flotation process were found to be free from grains sized over $0.2 \mathrm{~mm}$. Classification results for test no. 4 are shown in Tables $2-4$. The classification efficiency values reached $94-95 \%$, for a $718 \mathrm{~m}^{3} / \mathrm{h}$ feed output per hydrocyclone cluster. After two weeks of ceaseless system operation, the researchers observed no wear of the silicon carbide apex — the hydrocyclone element most exposed to abrasion.

Sizes of inlets, apexes and vortex finders during tests:

$\begin{array}{clll}\text { H } 1: & d_{o}-125 \mathrm{~mm}, & d_{w}-60 \mathrm{~mm}, & d_{p}-175 \mathrm{~mm}, \\ -\quad H 2: & d_{o}-125 \mathrm{~mm}, & d_{w}-50 \mathrm{~mm}, & d_{p}-175 \mathrm{~mm}, \\ - \text { H3: } & d_{o}-125 \mathrm{~mm}, & d_{w}-60 \mathrm{~mm}, & d_{p}-200 \mathrm{~mm} .\end{array}$

\section{Comparative tests of classification in $\mathrm{HC}$ Cavex and $\mathrm{HC500/12}{ }^{\circ}$ hydrocyclones in $\mathrm{Zn}$-Pb ore enrichment process}

\subsection{Characteristics of tested classification circuits}

The primary $\mathrm{Zn}-\mathrm{Pb}$ ore classification circuit at DPM „Olkusz-Pomorzany”, used to classify overflows from spiral classifiers, is equipped with Cavex hydrocyclones, characterised by a cylindrical section diameter of $400 \mathrm{~mm}$ with a conical section angle of $10^{\circ}$.

The cluster of eight hydrocyclones was also provided with an automatic control system. Currently, three hydrocyclones are in service at the optimal milling plant, with the following configurations of inlets, vortex finders and apexes:

- inlet $\left(d_{o}\right) \varnothing 94 \mathrm{~mm}$,

- vortex finder $\left(d_{p}\right) \varnothing 145 \mathrm{~mm}$,

- $\operatorname{apex}\left(d_{w}\right) \varnothing 60 \mathrm{~mm}$

and feed pressure ranging within $0.85-1.15$ bar.

After minor adaptation works, a new $\mathrm{HC} 500 / 12^{\circ}$ hydrocyclone was connected to the existing cluster in order to perform classification tests. 


\subsection{Classification conditions and results}

Three series of tests were performed for Cavex hydrocyclones, and six tests for the $\mathrm{HC}$ $500 / 12^{\circ}$ hydrocyclone. The inlets, vortex finders and apexes used in individual tests were as follows:

1) $d_{o}-\varnothing 100 \mathrm{~mm}$

$d_{p}-\varnothing 150 \mathrm{~mm}, \quad d_{w}-\varnothing 65 \mathrm{~mm}$,

2) $d_{o}-\varnothing 100 \mathrm{~mm}$,

$d_{p}-\varnothing 150 \mathrm{~mm}$,

$d_{w}-\varnothing 60 \mathrm{~mm}$,

3) $d_{o}-\varnothing 100 \mathrm{~mm}$,

$d_{p}-\varnothing 150 \mathrm{~mm}$,

$d_{w}-\varnothing 70 \mathrm{~mm}$,

4) $d_{o}-\varnothing 100 \mathrm{~mm}$,

$d_{p}-\varnothing 175 \mathrm{~mm}$,

$d_{w}-\varnothing 72 \mathrm{~mm}$,

5) $d_{o}-\varnothing 100 \mathrm{~mm}$,

$d_{p}-\varnothing 175 \mathrm{~mm}$,

$d_{w}-\varnothing 65 \mathrm{~mm}$,

6) $d_{o}-\varnothing 125 \mathrm{~mm}$,

$d_{p}-\varnothing 175 \mathrm{~mm}$,

$d_{w}-\varnothing 72 \mathrm{~mm}$.

Test results for ore classification in Cavex hydrocyclones are shown in Table 5 and Table 6, and for HC500/12 ${ }^{\circ}$ hydrocyclones — in Table 7.

The main criteria for the correct classification in hydrocyclones at DPM Olkusz-Pomorzany are: concentration of overflows, which should be close to $1350 \mathrm{~g} / \mathrm{dm}^{3}$, and as low as possible fraction of grain size class over $0.2 \mathrm{~mm}$. Therefore, in the case of the classification results for Cavex hydrocyclones, the third series of tests should be deemed optimal. Sieve analysis for that series of tests is shown below in Table 6.

\section{TABLE 5}

Results of ore classification in Cavex hydrocyclones

\begin{tabular}{|l|c|c|c|c|}
\cline { 2 - 5 } \multicolumn{1}{c|}{} & $\begin{array}{c}\text { Content of grain } \\
\text { class } \mathbf{- 0 , 0 3 6} \mathbf{~ m m} \\
\text { in underflow, } \\
{[\mathbf{\%}]}\end{array}$ & $\begin{array}{c}\text { Content of grain } \\
\text { class } \mathbf{+ 0 , 2} \mathbf{~ m m} \\
\text { in overflow, } \\
{[\%]}\end{array}$ & $\begin{array}{c}\text { Yield } \\
\text { of overflow, } \\
{[\mathbf{\%}]}\end{array}$ & $\begin{array}{c}\text { Efficiency } \\
\text { of classification, } \\
{[\%]}\end{array}$ \\
\hline I series of tests & 7,31 & 11,58 & 36,46 & 62,0 \\
\hline II series of tests & 10,10 & 2,63 & 37,33 & 77,8 \\
\hline III series of tests & 9,65 & 10,58 & 48,75 & 72,7 \\
\hline
\end{tabular}

When we compare the technological results of the above-mentioned tests, the most advantageous are those in test no. 5. Table 8 shows sieve analyses for classification products in that test. Class $+0.2 \mathrm{~mm}$ content in overflow are the same as in test no. 1, but with a much lower fraction of the finest class $-0.036 \mathrm{~mm}$ in the underflow and higher hydrocyclone capacity due to a larger vortex finder. Admittedly, the lowest class $+0.2 \mathrm{~mm}$ content values in overflow were achieved in tests 2 and 4 (ca. 2.5\%), but for the high finest class fraction in hydrocyclone underflow ( $26.8 \%$ and $35.9 \%$, respectively). 


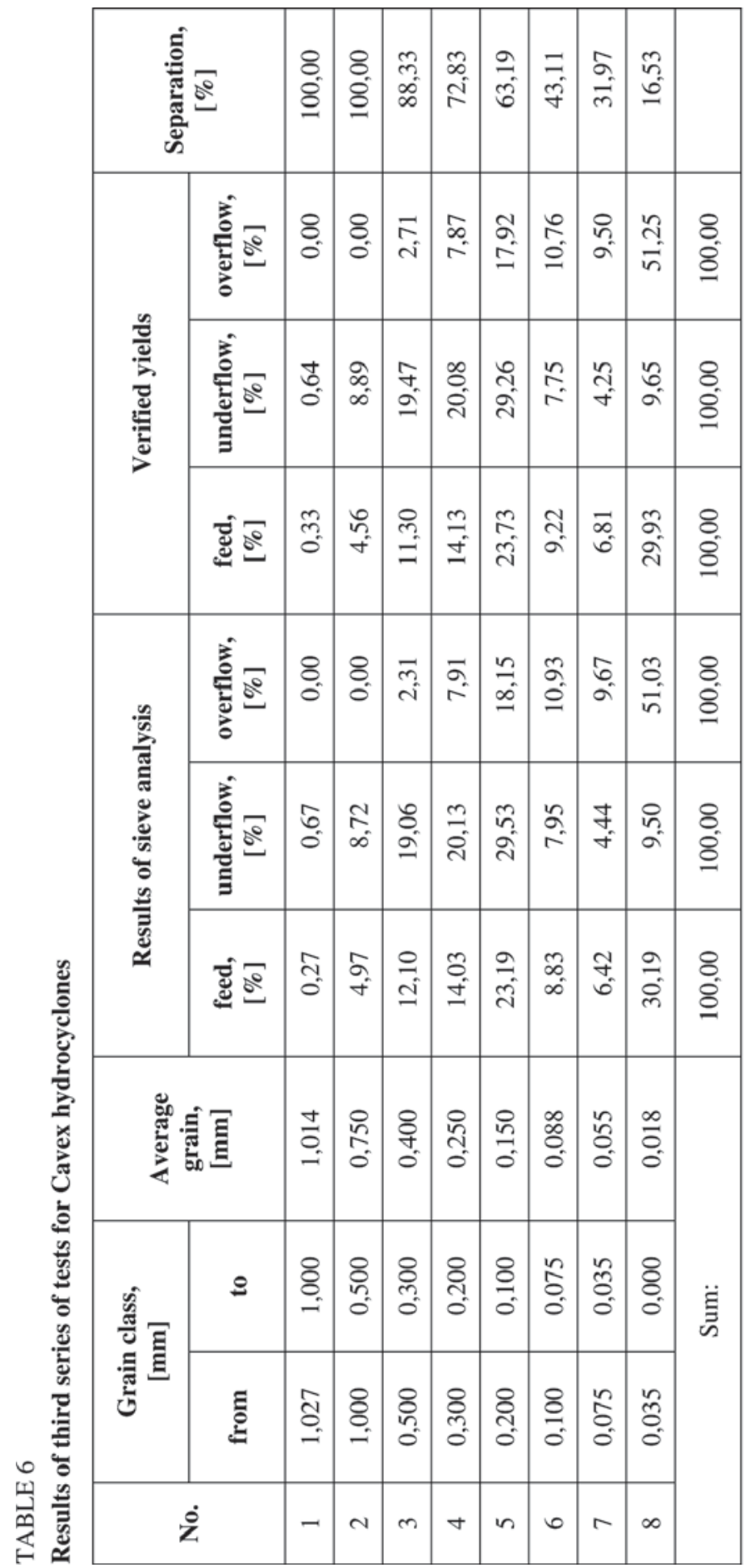




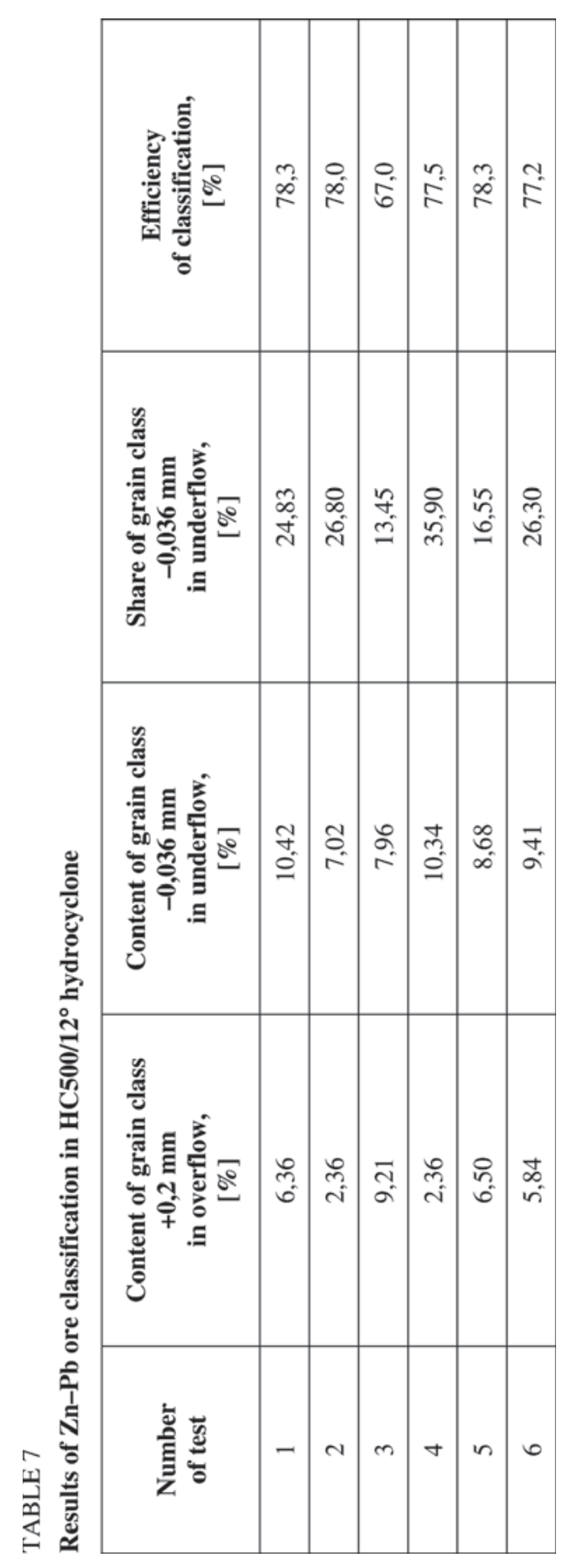




\begin{tabular}{|c|c|c|c|c|c|c|c|c|c|c|c|}
\hline & \multicolumn{2}{|c|}{ 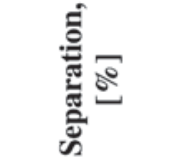 } & 8 & $\begin{array}{l}8 \\
8 \\
8\end{array}$ & \begin{tabular}{l}
$\infty$ \\
m \\
\multirow{\sigma}{}{}
\end{tabular} & 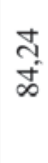 & $\frac{n}{N}$ & $\frac{\mathbb{Z}}{n}$ & $\begin{array}{l}\stackrel{\infty}{\sim} \\
\text { ని }\end{array}$ & $\begin{array}{l}\infty \\
n \\
n^{2}\end{array}$ & \\
\hline & \multirow{3}{*}{ 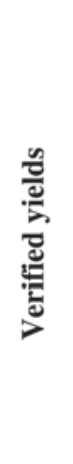 } & 爮 & 8 & 8 & $\tilde{n}$ & \begin{tabular}{l}
$\stackrel{\circ}{\Im}$ \\
\multirow{+}{*}{}
\end{tabular} & तु & ભે & $\frac{t}{2}$ & $\begin{array}{l}\text { N̦ } \\
\infty \\
\infty \\
\infty\end{array}$ & $\begin{array}{l}8 \\
8 \\
8\end{array}$ \\
\hline & & 产 & ñ & $\underset{\infty}{+}$ & ?2 & $\hat{\sigma}$ & $\begin{array}{l}\text { రె } \\
\text { సे }\end{array}$ & $\frac{\partial}{\infty}$ & $\stackrel{m}{\stackrel{9}{f}}$ & $\begin{array}{l}\infty \\
\infty \\
\infty\end{array}$ & $\begin{array}{l}8 \\
8 \\
8\end{array}$ \\
\hline & & 递 & $\bar{m}$ & $=$ & $\stackrel{0}{=}$ & $\begin{array}{l}\text { 它 } \\
\stackrel{2}{2}\end{array}$ & 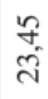 & वे & $\begin{array}{l}\infty \\
\infty \\
0 \\
0\end{array}$ & $\begin{array}{l}\text { నે } \\
\text { సे }\end{array}$ & $\begin{array}{l}8 \\
8 \\
8\end{array}$ \\
\hline & \multirow{3}{*}{ 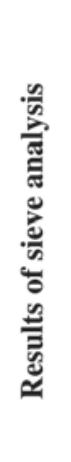 } & हैं & 8 & 8 & $\stackrel{0}{n}$ & $\stackrel{F}{F}$ & $\begin{array}{l}\text { ?. } \\
\stackrel{2}{n}\end{array}$ & $\stackrel{2}{\stackrel{+}{\circ}}$ & aे & $\frac{n}{\infty}$ & $\begin{array}{l}8 \\
8 \\
8\end{array}$ \\
\hline & & 窇 & n. & б. & $\stackrel{8}{\circ}$ & $\begin{array}{l}\text { 응 } \\
\text { - }\end{array}$ & 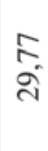 & ले & $\begin{array}{l}\stackrel{g}{\sigma} \\
\dot{+}\end{array}$ & $\begin{array}{l}\text { in } \\
\infty\end{array}$ & $\begin{array}{l}8 \\
8 \\
8\end{array}$ \\
\hline & & 赵 & กิ & $\hat{\sigma}$ & $\stackrel{ }{\text { 의 }}$ & $\begin{array}{l}\delta \\
\dot{ \pm} \\
\dot{ \pm}\end{array}$ & $\frac{a}{\ddot{\lambda}}$ & $\begin{array}{l}\infty \\
\infty \\
\infty\end{array}$ & $\underset{\text { İ }}{\text { ô }}$ & $\frac{a}{0}$ & $\begin{array}{l}8 \\
8 \\
8\end{array}$ \\
\hline '? & \multicolumn{2}{|c|}{ 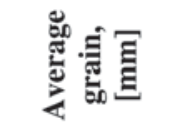 } & $\underset{0}{ \pm}$ & $\frac{\stackrel{n}{\circ}}{0}$ & $\begin{array}{l}8 \\
\text { ó } \\
\text { 。 }\end{array}$ & $\begin{array}{l}\text { స్ } \\
\text { ㅇ. }\end{array}$ & $\frac{i}{0}$ & $\begin{array}{l}\infty \\
\infty \\
0 \\
0\end{array}$ & $\begin{array}{l}n \\
\text { ஜ́ } \\
0\end{array}$ & $\frac{\infty}{0}$ & \multirow{4}{*}{ 悹 } \\
\hline 总 & \multirow{2}{*}{ 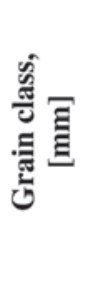 } & $\rho$ & 8 & $\begin{array}{l}8 \\
\text { ஜn } \\
\text { o }\end{array}$ & $\begin{array}{l}\text { రి } \\
\text { లn }\end{array}$ & ঠి & $\frac{8}{0}$ & م̂ & గి & 8 & \\
\hline 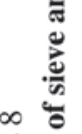 & & $\Xi$ & 응 & 8 & $\begin{array}{l}8 \\
8 \\
0 \\
0\end{array}$ & రి & $\begin{array}{l}\text { ঠి } \\
\text { గ్ }\end{array}$ & $\frac{8}{8}$ & ڤ్ & ช̂ & \\
\hline 气 & \multicolumn{2}{|c|}{$\dot{\mathbf{z}}$} & - & $N$ & $m$ & $\forall$ & $n$ & 0 & $r$ & $\infty$ & \\
\hline
\end{tabular}


Using $\mathrm{HC} 500 / 12^{\circ}$ hydrocyclone for $\mathrm{Zn}-\mathrm{Pb}$ ore classification at DPM Olkusz-Pomorzany demonstrated comparable results to the Cavex hydrocyclones in the main classification circuit already in operation there. Operation of both hydrocyclones is compared in Table 9. The comparison shows the optimal results for both machines.

\section{TABLE 9}

Comparison of classification in Cavex and $\mathrm{HC} 500 / 12^{\circ}$ hydrocyclones

\begin{tabular}{|l|c|c|c|}
\cline { 2 - 4 } \multicolumn{1}{c|}{} & $\begin{array}{c}\text { Content of grain class } \\
\mathbf{+ 0 , 2} \mathbf{~ m m} \\
\text { in overflow, } \\
{[\mathbf{\%}]}\end{array}$ & $\begin{array}{c}\text { Content of grain class } \\
\mathbf{- 0 , 0 3 6} \mathbf{~ m m} \\
\text { in underflow, } \\
{[\%]}\end{array}$ & $\begin{array}{c}\text { Efficiency } \\
\text { of classification, } \\
{[\%]}\end{array}$ \\
\hline Cavex & 7,31 & 11,58 & 72,7 \\
\hline HC500/12 & 6,50 & 8,68 & 78,3 \\
\hline
\end{tabular}

The technological parameters obtained for $\mathrm{HC} 500 / 12^{\circ}$ hydrocyclone are higher than those for Cavex hydrocyclones. This is so because of the lower class $+0.2 \mathrm{~mm}$ content in overflow and class $-0.036 \mathrm{~mm}$ in underflow of $\mathrm{HC} 500 / 12^{\circ}$ hydrocyclone. These results have been obtained for slightly higher $\mathrm{HC} 500 / 12^{\circ}$ hydrocyclone efficiency.

\section{Summary}

The examples presented confirm the considerable potential as regards using the new HC500/12 ${ }^{\circ}$ hydrocyclone in various operating conditions with different materials, following the proper selection of its operating parameters. New HC500/12 ${ }^{\circ}$ type hydrocyclones should have a positive effect on classification effectiveness of mineral raw materials.

Moreover, the new solution guarantees:

- a wider application range as regards the granulation of classified materials,

- maintaining stable operating conditions in classification circuits due to employed automatic control systems,

- the reduced energy consumption of pumping systems supplying hydrocyclones due to good classification results at lower pressure of supplied feed,

- extended service life of individual hydrocyclone elements as a result of using antiabrasive silicon carbide-based linings.

\section{REFERENCES}

[1] Chen J., Chu K.W., Zou R.P.: Prediction of the performance of dense medium cyclones in coal preparation. Minerals Engineering, 31, 2012 
[2] Kuang S.B., Chu K.W., Vince A.: Numerical study of liquid-gas-solid flow in classifying hydrocyclones: Effect of feed solids concentration, Minerals Engineering, 31, 2012

[3] Myszkowski P.: Classification in hydrocyclones in closed grinding circuits. Mining and Geology. Vol. 6, Book 2, 2011

[4] Narasimha M., Brennan M.S.: CFD modeling of hydrocyclones: Prediction of particle size segregation. Minerals Engineering, 39, 2012

[5] Szczerba E. et al.: Research on the possibility of changes in the classification and thickening process while enriching copper ores by using a new type of hydrocyclone. IMN Report No. 6907, 2010

[6] Wieniewski A., Szczerba E.: Research on developing a new structure of thickening-classifying hydrocyclones. IMN Report No. 6937 on implementation of the Key Project — POIG 01.03.01-24-019/08-00, 2011

[7] Wieniewski A., Zachariasz T., Szczerba E.: Current problems in the processes of classifying Polish ores of non-ferrous metals. International Copper Ore Mining Congress, Lubin 2012. 